Abstracta Iranica Abstracta Iranica

Revue bibliographique pour le domaine irano-aryen

Volume 28 | 2007

Comptes rendus des publications de 2005

\title{
La Perse antique. Paris, Les Belles lettres, 2005, 298 p. (Guide Belles Lettres des Civilisations, 20).
}

\section{Domenico Agostini}

\section{(2) OpenEdition \\ 12 Journals}

Édition électronique

URL : http://journals.openedition.org/abstractairanica/14392

ISSN : 1961-960X

\section{Éditeur :}

CNRS (UMR 7528 Mondes iraniens et indiens), Éditions de l'IFRI

\section{Édition imprimée}

Date de publication : 15 mai 2007

ISSN : 0240-8910

\section{Référence électronique}

Domenico Agostini, « La Perse antique. Paris, Les Belles lettres, 2005, 298 p. (Guide Belles Lettres des Civilisations, 20). », Abstracta Iranica [En ligne], Volume 28 | 2007, document 47, mis en ligne le 18 septembre 2007, consulté le 25 septembre 2020. URL : http://journals.openedition.org/

abstractairanica/14392

Ce document a été généré automatiquement le 25 septembre 2020.

Tous droits réservés 


\title{
La Perse antique. Paris, Les Belles lettres, 2005, 298 p. (Guide Belles Lettres des Civilisations, 20).
}

\author{
Domenico Agostini
}

1 Il n'est jamais facile de réussir un ouvrage de vulgarisation sur un thème dont on est spécialiste du fait de la complexité même des références, de leur densité, et de la difficulté à les trier. En effet un livre pour grand public requiert des choix, avec le risque que ceux-ci ne soient pas toujours faits à bon escient et soient parfois même regrettables. Huyse a toutefois rempli totalement sa mission de donner vie à un guide sur la Perse antique : il donne aux étudiants les outils de base qui leur permettront d'acquérir d'autres connaissances, il séduit les amoureux des civilisations antiques ainsi que les voyageurs en attisant leur curiosité et il attire l'intérêt des iranologues sur des points particuliers.

2 L'ouvrage met en opposition diverses thématiques d'ordre historico-religieux, artistique, littéraire et social qui se déroulent tout au long des trois grands empires iraniens de l'Antiquité, celui des Achéménides (558-330 av. J.-C.), des Arsacides (247 av. J.-C.-224 ap. J.-C.) et enfin celui des Sassanides (224-651 ap. J.-C.).

3 Après une brève introduction qui permet de situer le sujet (pp. 9-13), le premier chapitre (pp. 29-56) offre une ébauche de la période historique, des Achéménides aux Sassanides, et se termine avec une chronologie générale qui remonte jusqu'à la Préhistoire de l'Iran. Les second (pp. 57-74), troisième (pp. 75-94) et quatrième chapitres décrivent respectivement la composition urbaine et les infrastructures des trois empires (les villes principales Persépolis, Suse, Nisā, Fīrūzābād, etc., les voies de circulation, et les schémas d'irrigation), l'organisation politique et sociale (l'image du roi, la composition des couches sociales, la justice, les impôts, l'armée) et la vie économique (le rôle primordial de l'agriculture, le développement de l'artisanat et du commerce, les poids et mesures, les divers systèmes monétaires). Le cinquième chapitre (pp. 113-129) est consacré à la conception du temps et de l'espace (les sept kišvars " continents », la division de l'empire sassanide suivant les quatre points cardinaux, le 
système de mesure du temps, les calendriers, les jours de fête, les rites ainsi que les étapes de la vie).

4 Le sixième (pp. 131-158) et le septième (pp. 159-191) chapitres traitent respectivement des diverses religions pratiquées en Iran (en particulier le mazdéisme achéménide, arsacide et sassanide, le zurvanisme, le manichéisme mais aussi le mazdakisme, le christianisme et d'autres encore), de la littérature et des différentes sciences (les langues et écritures, l'Avesta, la tradition nationale du xwadāy-nāmag, les inscriptions en vieux-perse, parthe et moyen-perse, la littérature parthe, moyen-perse zoroastrienne et moyen-perse manichéenne, les textes lexicographiques, scientifiques et astrologiques). En ce qui concerne les trois derniers chapitres, le huitième, riche en illustrations (pp. 193-213), est consacré aux arts (architecture, sculpture, arts décoratifs, musique et danse), le neuvième (pp. 215-224) aux loisirs (le jeu d'échec, le polo, le backgammon, l'équitation, la chasse, les " paradis ", les banquets et la cuisine), et enfin le dixième (pp. 225-246) à la vie privée (l'onomastique, l'habitat, l'éducation ; les femmes, la sexualité, l'habillement; à la page 241 la représentation des différents korymboi « couronnes » des souverains sassanides est particulièrement intéressante).

Le livre s'achève sur des repères biographiques, une orientation bibliographique qui permet un approfondissement ultérieur des sujets évoqués et différents indices.

6 D'une lecture agréable, ce livre a le mérite de transmettre d'une manière «non eurocentrique » la naissance, le développement et la fin de ces grands empires iraniens trop longtemps considérés, à tort, comme porteurs de barbarie et de décadence.

INDEX

Thèmes : 3.0. Généralités

\section{AUTEURS}

DOMENICO AGOSTINI

Paris 